\title{
A Statistical Analysis on Instability and Seasonal Component in the Price Series of Major Domestic Groundnut Markets in India
}

\author{
A.S. Dudhat*, Pushpa Yadav and B. Venujayakanth
}

College of Agriculture, Junagadh Agricultural University, Amreli, Gujarat, India

*Corresponding author

A B S T R A C T

\begin{tabular}{|l|}
\hline Ke y w o r d s \\
Price variation, \\
$\begin{array}{l}\text { Instability, } \\
\text { Seasonality, Price } \\
\text { signals and Trend } \\
\text { model. }\end{array}$ \\
\hline Article Info \\
\hline $\begin{array}{l}\text { Accepted: } \\
10 \text { September } 2017 \\
\text { Available Online: } \\
\text { 10 November } 2017\end{array}$ \\
\hline
\end{tabular}

Keywords

Price variation

Instability,

Seasonality, Price

model.

\section{Introduction}

Groundnut is cultivated in tropical , subtropical and warm temperate regions between $40^{\circ} \mathrm{N}$ and $40^{\circ} \mathrm{S}$ latitudes. The production is largely confined to Asian and African countries. Asia accounts for about 50 per cent of area and 60 per cent of world production of groundnut with largest share of India (more than 20\%) in the groundnut coverage, followed by China (more than 18\%). More than 85 per cent production of groundnut comes from five states namely Gujarat (38\%), Andhra Pradesh (16\%), Tamil Nadu (14\%), Rajasthan (9\%) and Karnataka (8\%) (Anon., 2014).

Kurnool in Andhra pradesh, Rajkot in Gujarat and Villupuram in Tamil Nadu are identified as potential district of groundnut production. (Anon., 2014). Market arrivals and transaction are high in these markets. So it is significant to study the performance of groundnut markets in these districts and price fluctuation occurring in these markets.

Market price instability and seasonal component study in these markets gives a scope to the policy makers and farmers in regard to the policy making and investment activity. Fluctuations in commodity prices have always been a major concern of the producers as well as the consumers as they affect their decision and planning process (Sundaramoorthy et al., 2014). So an advanced estimate of price and price 
fluctuation is required by farmers to stabilize their income in one hand and in other hand it helps the policy makers to adopt suitable policy measures to control the instability. The present research work was carried out with objectives includes; to compare the price variation of groundnut markets under study using descriptive statistics. And to measure the Price instability market wise. Also measure the price seasonality by fitting trend model.

Rakesh Sihmar (2014) studied Growth and Instability in Agricultural Production in Haryana by using Cuddy Della Valley Index (CDVI) and reported that rice and wheat were more stable (15) but the coarse cereals and pulses highly instable $(>30)$ in area and production in Haryana.

\section{Materials and Methods}

The methodologies that are presented here to analyze instability and market integration are statistically sound, which was collected from various time series literatures available.

\section{Source of data}

The time series data on price of groundnut market for the period 1996 to 2016 had been obtained from Directorate of Agriculture and co-operation, Department of Agriculture and Cooperation, Government of India.

\section{Selection for markets}

Selection of markets on the basis of maximum arrival of Groundnut, i.e. Rajkot (Gujarat), Kurnool (Andhra Pradesh) and Villupuram (Tamil Nadu) districts.

\section{Recorded observations}

A Time series data on price of groundnut crop was obtained from 1996-April to 2016-April of selected markets.

\section{Statistical analysis}

\section{Cuddy Della Valle index}

Cuddy Della Valle Instability index (Cuddy and Della Valle 1978) is a modification of coefficient of variation to accommodate trend present in the data, which is commonly present in economic time series data. This method is superior over the scale dependent measures such as standard deviation. The Cuddy Della Valle index (CDVI) is calculated as follows:

$\mathrm{CDVI}=\mathrm{CV} \sqrt{\mathrm{X}}$

Where, $\mathrm{X}=1-\overline{\mathrm{R}}^{2}, \mathrm{CV}$ is coefficient of variation, and $\overline{\mathrm{R}}^{2}$ is adjusted coefficient of determination. The ranges of CDVI (Rakesh Sihmar, 2014) are given as follows:

Low instability $=$ between 0 and 15

Medium instability $=$ greater than 15 and lower than 30

High instability $=$ greater than 30

\section{Test of unit root}

Time series data are said to be random or stochastic process. The random or stochastic process is a collection of random variable ordered in time. If we let $\mathrm{Y}$ denote a random variable, and it is continuous, we denote it as $\mathrm{Y}(\mathrm{t})$, but if it is discrete, we denote it as $\mathrm{Y}_{\mathrm{t}}$. since most economic data are collected as discrete points in time, so for our purpose we use the notation $\mathrm{Y}_{\mathrm{t}}$

A type of stochastic process that has received a great deal of attention and scrutiny by time series analyst is the so called stationary stochastic process.

A stochastic process is said to be stationary if its mean and variance are constant over time 
and the value of the covariance between the two periods depends only on the distance or gap or lag between the two time periods and not the actual time with which the covariance is computed.

The time series is said to be stationary if it possess following properties

Mean: $E\left(Y_{t}\right)=\mu$

$\operatorname{Var}\left(\mathrm{Y}_{\mathrm{t}}\right)=\mathrm{E}\left(\mathrm{Y}_{\mathrm{t}}-\mu\right)^{2}=\sigma^{2}$

Covariance $($ auto covariance $)=\mathrm{E}\left[\left(\mathrm{Y}_{\mathrm{t}^{-}} \mu\right)\right.$ $\left.\left(\mathrm{Y}_{\mathrm{t}+\mathrm{k}}-\mu\right)\right]=\gamma_{\mathrm{k}}$

In short we can say the mean, variance, and auto covariance (at various lag) remain the same no matter at what point we measure them; that is they are time invariant. it is very important to test whether the time series is stationary or not because if a time series is not-stationary then we can study its behavior only for the time period under consideration, it is not possible to generalize it to other periods and therefore we can't able to forecast such a time series data. So in order to test stationary or unit root we use the famous test known as Augmented Dickey-Fuller (ADF) Test

\section{Augmented Dickey-Fuller (ADF) test}

The ADF test consists of estimating the following regression:

$\Delta \mathrm{Y}_{\mathrm{t}}=\beta_{1}+\beta_{2} \mathrm{t}+\delta \mathrm{Y}_{\mathrm{t}-1}+\sum_{\tilde{i}=1}^{m} \alpha_{\mathrm{i}} \Delta \mathrm{Y}_{\mathrm{t}}+\varepsilon_{\mathrm{t}}(1)$

Where,

$\varepsilon_{\mathrm{t}}=$ pure white noise error term

$\Delta \mathrm{Y}_{\mathrm{t}-1}=\left(\mathrm{Y}_{\mathrm{t}-1}-\mathrm{Y}_{\mathrm{t}-2}\right), \Delta \mathrm{Y}_{\mathrm{t}-2}=\left(\mathrm{Y}_{\mathrm{t}-2}-\mathrm{Y}_{\mathrm{t}-3}\right)$.etc.

$\mathrm{m}=$ number of lag length and it is determined based on the Akaike, Schwarz information criteria.
ADF test

Null hypothesis $\mathrm{H}_{0}: \delta=0$

Alternative hypothesis $\mathrm{H}_{1}: \delta<0$

The possibility of acceptance and rejection of $\mathrm{H}_{0}$ is based on the tau statistic

Estimation procedure of tau statistic $(\tau)$ is as follows:

Estimate the equation (1) by OLS method.

To compute absolute value of the $(|\tau|)$, divide the estimated coefficient of $\mathrm{Y}_{\mathrm{t}-1}$ by its standard error and refer to the DF (DickeyFuller) table.

If the computed absolute value of the $(|\tau|)$ exceeds the absolute DF or MacKinnon critical tau values, we reject that $\delta=0$, in which case the time series if stationary.

On the other hand if the computed absolute value of the $(|\tau|)$ does not exceeds the absolute DF or MacKinnon critical tau values, we accept that $\delta=0$, in which case the time series if non stationary.

\section{Results and Discussion}

According to objective of the present research work, polynomial models (Linear and Quadratic) were fitted to price levels of three major domestic groundnut markets viz., Kurnool (Andhra Pradesh), Rajkot (Gujarat) and Villupuram (Tamil Nadu) to measure the instability and seasonality.

\section{Summary statistics}

The descriptive statistics of price series of all the three markets viz., Kurnool (Andhra Pradesh), Rajkot (Gujarat) and villupuram (Tamil Nadu) are presented in Table 1. It indicate that all the three markets have positively skewed $\left(\gamma_{1}>0\right)$ and platykurtic $\left(\beta_{2}\right.$ 
< 3) distribution. The positive skewness criteria is also confirmed by the measure of central tendency viz., mean, median and mode i.e., for all the three markets mean $>$ median > mode which is one of the important property of positively skewed distribution, none of the market does not satisfy the normal distribution criteria $\left(\gamma_{1}=0\right.$ and $\left.\beta_{2}=3\right)$ which itself indicate that the price level of all the three markets exhibit fluctuation. The range of Kurnool, Rajkot and villupuram market is 4215.04, 4224.45 and 6199.67 which indicate the wide variation in the price levels and the standard deviation is also high.

\section{Trend model}

To measure price instability and price seasonality it is necessary to fit trend model to the price series. The instability index and seasonal factor are calculated based on the fitted trend. The result of fitted trend model for three markets is given as under.

\section{Fitting trend model in Kurnool market of Andhra Pradesh}

Trend is one of the components of time series data which means changes in the value of a variable in accordance with time, fitting of trend model is done by regressing the variable under consideration on chronological time period. This approach was performed to fit trend in Kurnool market and the result are presented in Table 2.

It reveals that both linear and quadratic trend coefficients were highly significant and the adjusted R-squared value was also high. The significance in coefficients were also supported by the F-statistic significance. The Akaike Information Criteria (AIC) and Schwarz Information Criteria (SIC) value were also comparatively low. Thus the fitted model was adequate to describe trend in the data.

In addition to this, the actual and fitted data are depicted graphically in figure 1. The residuals from the fitted model resemble white noise because they were almost within the two standard error limits. It is clear that the fitted quadratic trend model was appropriate for Kurnool market in measuring instability and seasonal factor.

\section{Fitting trend model in Rajkot market of Gujarat}

In Rajkot market, quadratic trend model did not adequately describe the data due to its insignificant trend coefficient and low adjusted-R squared value but the linear trend model which was presented in the Table 3 reveals that the trend coefficient was highly significant and it was also supported by the Fstatistic significance.

The AIC, SIC and adjusted-R square value for this linear trend were also comparatively low. Since only up to second degree polynomial trend model was performed, out of this two models, linear model was found to be adequately describe the data. The actual, fitted and residual of the fitted model is depicted in the figure 2 . It shows the residuals obtained from the fitted linear model are within the two standard error limits. So this model was appropriate for Rajkot market to measure instability and seasonality. 
Augmented Dickey-Fuller (ADF) test

\begin{tabular}{|c|c|c|l|}
\hline Series & $\mathrm{H}_{0}$ & $\mathrm{H}_{1}$ & $\rho$ \\
\hline Non stationary & Accepting & Rejecting & Presence \\
\hline Stationary & Rejecting & Accepting & Absence \\
\hline
\end{tabular}

Table.1 Summary statistics of price series

\begin{tabular}{|l|c|c|c|}
\hline \multirow{2}{*}{\multicolumn{1}{c|}{ Statistic }} & \multicolumn{3}{c|}{ Groundnut Market } \\
\cline { 2 - 4 } & Kurnool & Rajkot & Villupuram \\
\hline Mean & 2304.92 & 2380.62 & 3091.88 \\
\hline Median & 1800.00 & 1925.43 & 2572.73 \\
\hline Mode & 1350.00 & 1260.00 & 2025.00 \\
\hline Maximum & 5315.04 & 5174.45 & 7549.67 \\
\hline Minimum & 1100.00 & 950.00 & 1350.00 \\
\hline Standard deviation & 1087.99 & 1110.71 & 1443.08 \\
\hline Skewness & 0.94 & 0.82 & 0.92 \\
\hline Kurtosis & 2.68 & 2.52 & 2.77 \\
\hline
\end{tabular}

Table.2 Estimates of fitted quadratic trend model for Kurnool market

\begin{tabular}{|c|c|c|}
\hline Variables/parameters & Estimates & \\
\hline Intercept & $1346.11^{* * * * *}$ & \\
\hline Linear trend & $-3.86^{* * *}$ & \\
\hline Quadratic trend & $0.07^{* * *}$ & \\
\hline R-squared 0.88 & & \multirow{3}{*}{$\begin{aligned} \mathrm{AIC} & =14.77 \\
\mathrm{SIC} & =14.82\end{aligned}$} \\
\hline Adjusted R-squared 0.87 & & \\
\hline F-statistic $819.86^{* * * *}$ & & \\
\hline
\end{tabular}

$*, * *$ and $* * *$ indicate significance at $10 \%, 5 \%$ and $1 \%$ level respectively.

Value in brackets () are corresponding standard errors.

Table.3 Estimates of fitted linear trend model for Rajkot market

\begin{tabular}{|c|c|c|}
\hline Variables/parameters & Estimates & \\
\hline $\begin{array}{l}\text { Intercept } \\
\text { Linear trend }\end{array}$ & $\begin{array}{l}642.04^{* * * *}(62.15) \\
14.36^{* * *}(0.45)\end{array}$ & \\
\hline R-squared 0.82 & & \\
\hline $\begin{array}{l}\text { Adjusted R-squared } 0.82 \\
\text { F-statistic } 104133^{* * * *}\end{array}$ & & $\begin{array}{l}\mathrm{AIC}=15.19 \\
\mathrm{SIC}=15.22\end{array}$ \\
\hline
\end{tabular}

$*$,** and $* * *$ indicate significance at $10 \%, 5 \%$ and $1 \%$ level respectively.

Value in brackets () are corresponding Standard Errors. 
Table.4 Estimates of fitted quadratic trend model for Villupuram market

\begin{tabular}{|c|c|}
\hline Variables/parameters & Estimates \\
\hline Intercept & $1781.38^{* * * *} \quad(100.68)$ \\
\hline Linear trend & $-4.28^{* *}(1.92)$ \\
\hline Quadratic trend & $0.09^{* * * *} \quad(0.01)$ \\
\hline R-squared 0.87 & \\
\hline Adjusted R-squared 0.87 & $\mathrm{AIC}=15.35$ \\
\hline F-statistic $817.11^{* * *}$ & $\mathrm{SIC}=15.38$ \\
\hline
\end{tabular}

$*, * *$ and $* * *$ indicate significance at $10 \%, 5 \%$ and $1 \%$ level respectively.

Value in brackets are corresponding Standard Errors.

Table.5 Instability of the major domestic markets

\begin{tabular}{|l|l|l|l|l|}
\hline Market & Adjusted-R square & CV & CDVI & Range \\
\hline Kurnool & 0.87 & 47.20 & 16.90 & Medium \\
\hline Rajkot & 0.82 & 46.65 & 20.20 & Medium \\
\hline Villupuram & 0.87 & 46.67 & 16.71 & Medium \\
\hline
\end{tabular}

Table.6 Seasonal Factor for Kurnool market

\begin{tabular}{|l|c|}
\hline Month & Seasonal Factor (S.F) \\
\hline April & 10.78 \\
\hline May & 14.43 \\
\hline June & 89.96 \\
\hline July & 24.98 \\
\hline August & 117.88 \\
\hline September & 262.12 \\
\hline October & 47.16 \\
\hline November & -66.42 \\
\hline December & -118.95 \\
\hline January & -156.40 \\
\hline February & -98.17 \\
\hline March & -66.26 \\
\hline
\end{tabular}


Table.7 Seasonal factor for Rajkot market

\begin{tabular}{|l|c|}
\hline Month & Seasonal Factor (S.F) \\
\hline April & 152.90 \\
\hline May & 77.62 \\
\hline June & 84.66 \\
\hline July & 127.81 \\
\hline August & 100.75 \\
\hline September & -45.56 \\
\hline October & -267.23 \\
\hline November & -177.18 \\
\hline December & -17.76 \\
\hline January & -21.58 \\
\hline February & -43.23 \\
\hline March & 16.08 \\
\hline
\end{tabular}

Table.8 Seasonal factor for Villupuram market

\begin{tabular}{|l|c|}
\hline Month & Seasonal Factor (S.F) \\
\hline April & 62.56 \\
\hline May & 75.57 \\
\hline June & 361.89 \\
\hline July & 349.45 \\
\hline August & 269.21 \\
\hline September & 336.80 \\
\hline October & -44.16 \\
\hline November & -188.82 \\
\hline December & -114.93 \\
\hline January & -314.48 \\
\hline February & -399.94 \\
\hline March & -398.38 \\
\hline
\end{tabular}

Fig.1 Fitted quadratic trend model for Kurnool market

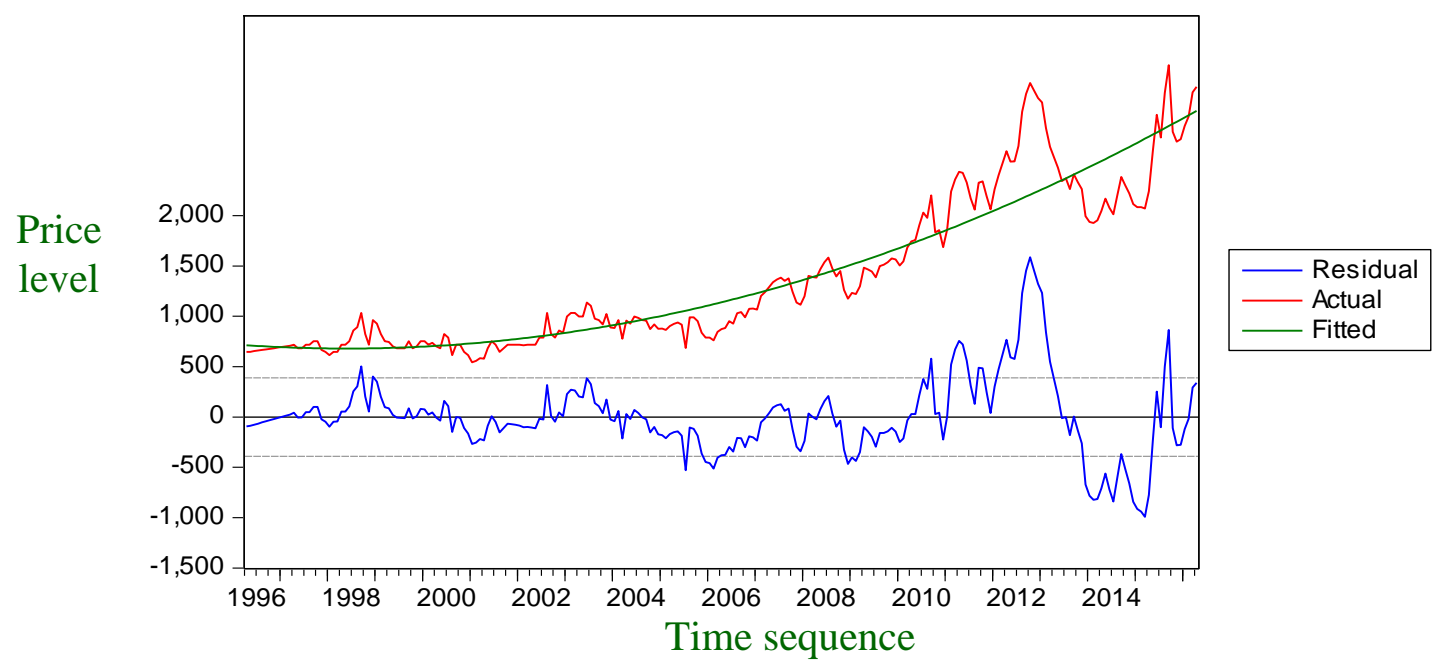


Fig.2 Fitted linear trend model for Rajkot market

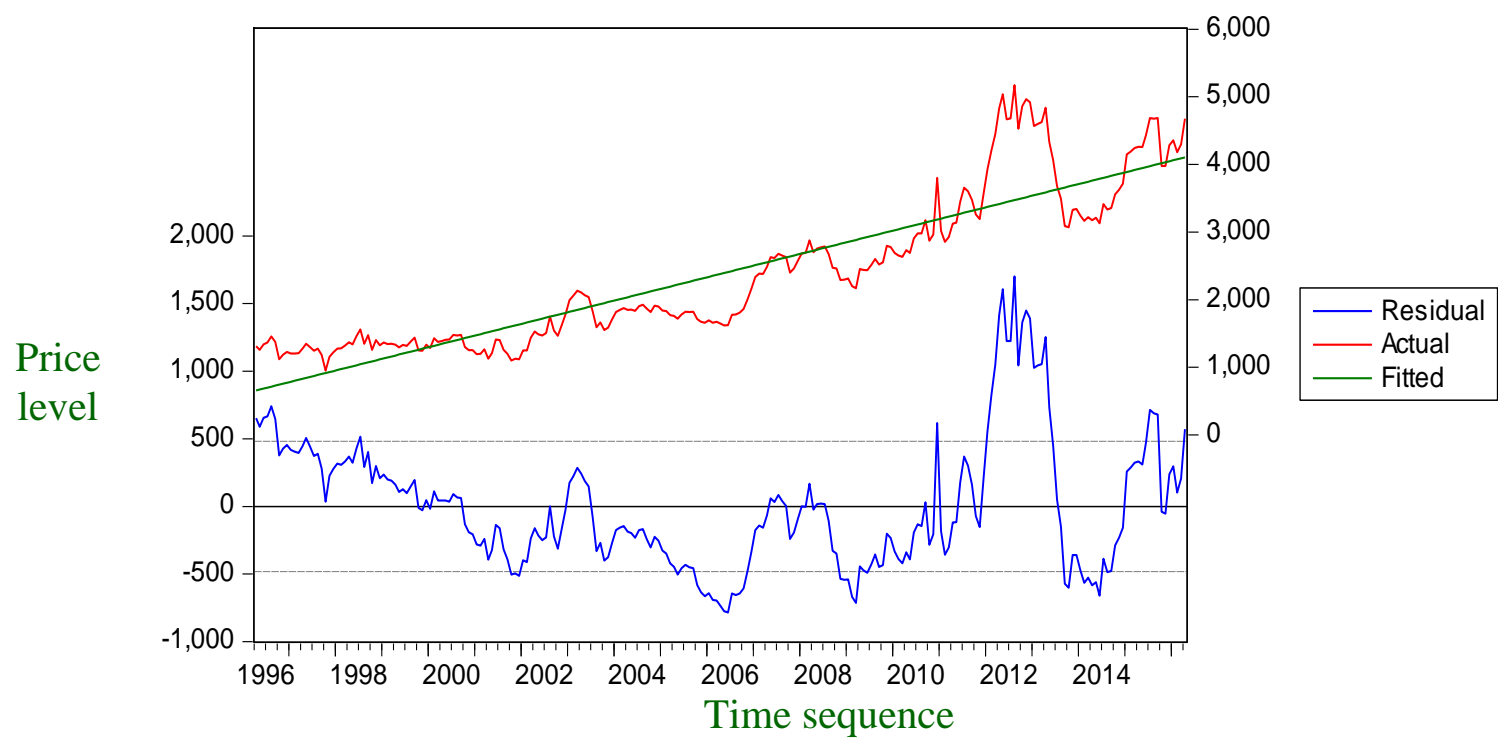

Fig.3 Fitted quadratic model for Villupuram market

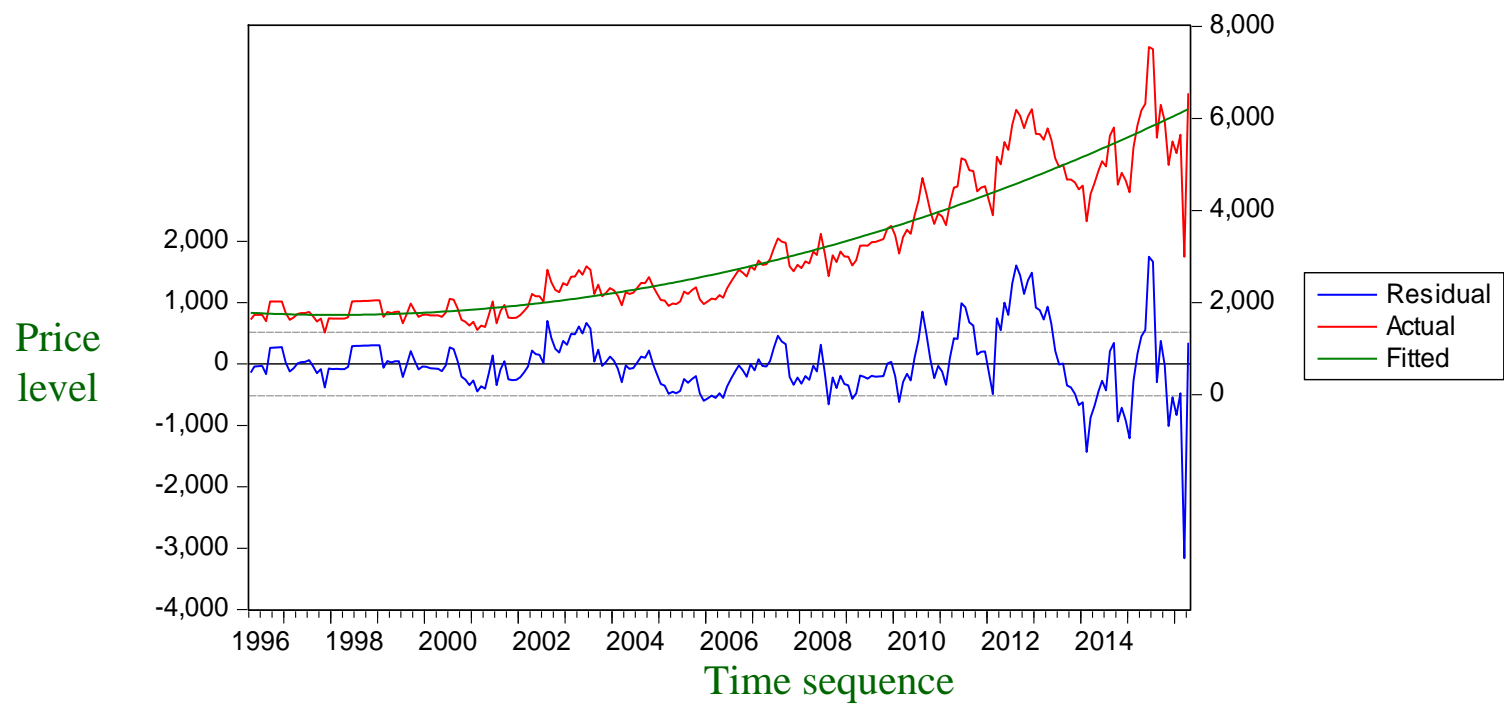

Fitting trend model in Villupuram market of Tamil Nadu

The result of trend model for Villupuram market is presented in Table 4. It reveals that both linear and quadratic trend coefficients were highly significant and the adjusted R-squared value was also high. The significance of coefficients was also supported by the Fstatistic significance. The AIC and SIC value were also comparatively low. Thus the fitted model was adequate to describe trend in the data.

In addition to this the actual and fitted data are depicted graphically in figure 3 . It is clear that the actual data reverting to its mean value (fitted value) was maximum and much of the residuals were within the standard error limits. So this model was appropriate for Villupuram market to measure instability and volatility. 


\section{Cuddy Della Valle Index (CDVI)}

In time series literature, instability in the data is measured by Cuddy Della Valle Instability index because this index accommodate trend present in the data which is not done by the commonly used instability measure i.e. Coefficient of Variation (CV). The latter measures instability around mean but the former measures instability around the trend. Since time series data contain trend, it should be detrended in order to measure instability in a statistically sound manner. So CDVI was utilized to measure instability in all the three markets and the result are presented in the Table.5. It reveals that instability for all the three markets was quite moderate (above 15).

In three markets, the instability of Rajkot market was quite higher than others it indicates that the persistence of volatility may be higher in Rajkot market than other two markets.

\section{Seasonal adjustment}

Unlike trend, seasonality is also one of the components in time series data. It mainly occurs in time series data of price, where the rise and fall in price is also subjected by the seasonal changes. In order to validate the estimation, the data should be adjusted seasonally. It is done by measuring the seasonal factor based on the fitted trend model and then adjusting that factor with the original data. The result of seasonal factor estimated by using the fitted trend model for Kurnool, Rajkot and Villupuram market are presented in the Tables 6, 7 and 8. The result are presented for only the first twelve month i.e., 12 data points because the seasonal factor measured for a month during a particular year was same for all the year i.e. the seasonal factor was irrespective of year. In all the three markets the instability was not low. As compare to the
Kurnool and Villupuram market, the instability in the Rajkot market was quite high. The seasonal component was estimated by fitting the quadratic trend in Kurnool and Villupuram market and linear trend in Rajkot market.

The farmer can use this price signals to plan their future production. In order to stabilize the price by adopting some price stabilization programme, this will ensure better farm income.

\section{References}

Anonymous. 2014. Report of Status paper on Oilseeds. Ministry of Agriculture. Department of Agriculture and Cooperation. Oilseed Division. New Delhi, India. Manager of publication. pp.23-42. https://www.nmoop.gov.in, accessed on (25/04/2016).

Blay, J. K., SubbaRao, D. V. and Kumari, R. V. 2015.Price Dynamics and Market Integration of Sorghum and Millet Markets in Ghana. Research Journal of Agriculture and Forestry Sciences, 3(9):11-21.

Cuddy, J. D. A. and Della Valle, P. A. 1978.Measuring the instability in time series data. Oxford B. Econ. Stat., 40(1):7985.

Dickey, D. A. and Fuller, A. W. 1979.Distribution of the estimators for Autoregressive time series with a unit root. Journal of American Statistical Association, 74(366): 427-431.

Rakesh Sihmar. 2014. Growth and Instability in Agricultural Production in Haryana: A District level Analysis. International Journal of Scientific and Research Publications, 4(7):1-12.

Sundaramoorthy, C., Girish, K. J., Suresh, P. and Mathur, V.C. 2014. Market Integration and Volatility in Edible Oil Sector in India. Journal of the Indian Society of Agricultural Statistics, 68(1):67-76.

\section{How to cite this article:}

Dudhat, A.S., Pushpa Yadav and Venujayakanth, B. 2017. A Statistical Analysis on Instability and Seasonal Component in the Price Series of Major Domestic Groundnut Markets in India. Int.J.Curr.Microbiol.App.Sci. 6(11): 815-823. doi: https://doi.org/10.20546/ijcmas.2017.611.096 